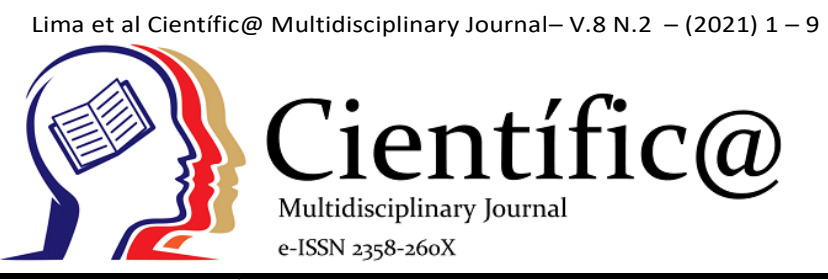

\title{
ORIGENS HISTÓRICAS DA VACINAÇÃO NO BRASIL
}

\author{
HISTORICAL ORIGINS OF VACCINATION IN BRAZIL
}

Allan Michel Bezerra Lima ${ }^{1}$, Antônio Jocilan dos Santos de Oliveira ${ }^{1}$, Ingrid Milena Lopes do Nascimento ${ }^{1}$, Joed Soares de Moura ${ }^{1}$, Marcos Vinicius Holanda Bessa ${ }^{1 *}$, Paulo Holanda Pinto Neto $^{1}$, Roberta Coely Lira Santos Rosado ${ }^{1}$, Sâmya Pires Batista de Azevedo ${ }^{1}$, Rodrigo José Fernandes de Barros ${ }^{2}$, Jamile Rodrigues Cosme de Holanda ${ }^{2}$

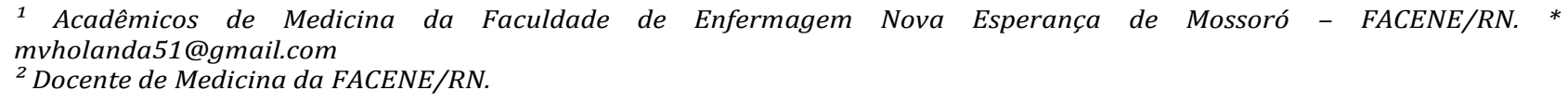

Info

Recebido: 07/2020

Publicado: $11 / 2021$

DOI: $10.37951 / 2358-260 X .2021 v 8 \mathrm{i} 2.5898$

ISSN: 2358-260X

\section{Palavras-Chave}

Vacina; Brasil; História.

Keywords:

Vaccine; Brazil; History.

\section{Resumo}

Desde o início da humanidade, há a busca por uma melhor qualidade de vida, bem como há o surgimento de algumas patologias, e dessa forma necessita-se da criação de técnicas que permitam a prevenção de doenças, principalmente as infectocontagiosas. 0 presente estudo se propõe a apresentar, por meio de uma ampla abordagem teórica, as questões em torno do avanço da vacinação no Brasil, o processo de defesa da população por meio de imunizantes e quais os avanços considerados pela medicina nesse processo, que tem se mostrado tão importante no período de pandemia pelo qual o mundo atravessa. Para tal foi realizado uma revisão da literatura embasada no periódico CAPES, com as palavras chaves "vacina", "Brasil", "princípio", "origem" de forma associada com o operador booleano "AND", quanto aos filtros aplicados foram a de estar disponível na integra de forma online e o do texto encontrar-se em português, não sendo aplicado o filtro de período de tempo, já que objetivava encontrar artigos que mencionassem o início da vacinação no Brasil. Ressalta-se que alguns sites também foram consultados, como o da Fiocruz. O qual possibilitou realizar um resgate histórico sobre o processo de vacinação, sua origem e o início da obrigatoriedade da mesma no Brasil.

\section{Abstract}

Since the beginning of humanity, there has been a search for a better quality of life, as well as the emergence of some pathologies, and thus it is necessary to create techniques that allow the prevention of diseases, especially infectious-contagious ones. This study proposes to present, through a broad theoretical approach, the issues surrounding the advancement of vaccination in Brazil, the process of defending the population through immunizations and what advances are considered by medicine in this process, which has been so important in the pandemic period that the world is going through. To this end, a literature review was carried out based on the CAPES journal, with the keywords "vaccine", "Brazil", "principle", "origin" in association with the Boolean operator "AND", as the filters applied were be available in full online and the text is in Portuguese, the time period filter not being applied, as it aimed to find articles that mentioned the beginning of vaccination in Brazil. It is noteworthy that some sites were also consulted, such as Fiocruz. Which made it possible to carry out a historical review of the vaccination process, its origin and the beginning of its obligation in Brazil.

\section{INTRODUÇÃO}

Estudos contemporâneos reforçam a tese já defendida de que, desde muito tempo, a busca por uma qualidade de vida sempre foi uma das principais premissas que regem o ser humano em seu espaçotempo. De certo, tal busca foi se tornando cada vez mais latente à medida que as doenças iam surgindo e tragando mais e mais vidas que, à época, ainda careciam 
de meios diversos e principalmente de imunodefensores que fossem capazes de modificar tal contexto da época (BERLINGUER, 1998).

Apesar da medicina ser uma tradição milenar, os estudos ainda escassos e as técnicas ainda rudimentares quando de sua existência e avanço, nem sempre permitiam que fosse possível encontrar formas que pudessem contornar os avanços das doenças e pragas. Neste cenário, surgiram muitos estudiosos que se debruçavam a descobrir técnicas que permitissem uma mudança nesse contexto, vindo a criar a vacina, por meio da defesa da tese de que era necessário reforçar a busca pelo tratamento das doenças, ao invés de focar propriamente na cura (BERLINGUER, 1998).

Conforme Berlinguer (1988) foi essa necessidade de buscar uma forma de amenizar o número de óbitos causados por doenças transmissíveis que as sociedades humanas possibilitaram o caminhar da humanidade rumo à descoberta das vacinas. Edward Jenner conseguiu, em 1789, criar aquilo que a medicina considera o projeto da primeira vacina, algo que Lesse e Doréa (2013) apontam como uma experiência transformadora, ao se valer de chances de que a pústula da varíola bovina, advinda de lesões de linfa de uma ordenhadora de vacas que foram aplicadas em um garoto utilizado como uma forma de cobaia, poderia trazer o processo de imunização naqueles que mantivessem contato com ela.

Apesar das controversas existentes em torno da chegada da vacina no Brasil e o processo de defesa das doenças em pacientes através de imunizantes inóculos, a ideia mais defendida, conforme aponta Chalhoub (1996), é que fora no ano de 1804 que a primeira dose chegaria em território brasileiro, à época, por força da influência exercida pelo então Marquês de Barbacena.

Para ter segurança em torno do meio de imunização até então inovador para a época, ele mandara cerca de sete crianças para Lisboa afim de que tomassem as doses no braço e verificar a suas reações para que se certificasse de sua eficácia (CHALHOUB, 1996). Após o experimento, naquele ano as primeiras vacinas seriam trazidas para a Bahia e de lá levadas ao Rio de Janeiro onde seriam utilizadas por meio da técnica de imunização braço a braço nos membros da Corte.

O sucesso do processo de vacinação no período foi tanto que, ainda segundo Chalhoub (1996), Dom João VI promoveu uma considerável aceitação da vacina por meio de toda a corte com a iniciativa de mandar que fossem vacinados seus filhos. Tamanho êxito fez com que em 1811, menos de uma década do início da vacinação no País, fosse criada uma comissão vacínica no Rio de Janeiro, fato inovador que fora reforçado com a publicação dos estudos de Jenner no País, o que contribuiu para uma difusão ainda maior sobre o êxito do processo.

Como é de se esperar, frente a qualquer fato novo, sobretudo para o período em que essa condição de desdobrou, houve uma maciça interferência dos poderes religiosos, que trataram de propagar ideias contrárias ao uso da vacina, rotulando-as como algo maléfico, capaz de gerar traumas e até maldições naqueles que fizessem uso dos compostos no braço (CHALHOUB, 1996).

A força na propagação de informações, ainda que falsas e controversas, por meio da forte presença de membros religiosos e suas celebrações, e ainda a influência por eles exercida, provocaram uma ruptura no êxito que a utilização das vacinas vinha tendo, fator que levou Dom João IV a decretar, em 1846, a obrigatoriedade da vacinação em todos os municípios do País por força de um decreto imperial. No Rio de Janeiro essa resistência ainda duraria por mais cem anos, e em 1904 culminou em um dos fatos mais conhecidos sobre a história da vacinação no País: a revolta da vacina. De acordo com Sevcenko (1993) o número de 
mortes que se acumulava naquele ano por conta da varíola, fez com que o Governo Brasileiro se valesse de argumentos que o fizesse aceitar como ideal a vacinação em massa no País.

O médico sanitarista Oswaldo Cruz foi um personagem simbólico nesse episódio, adotando uma série de medidas e propagando fatos que iam no sentido contrário às propostas que se elaboravam por boa parte da sociedade, que não aceitava a vacina como um método obrigatório. Hochman (1998) pontua que, após a Revolta, houve um amplo movimento que massificou a necessidade da vacina, frente ao contexto de carência no sistema sanitário do País, sendo um dos principais causadores das doenças da época. O país assistiria, anos depois, como uma espécie de avanço desse processo de evolução, uma reformulação nos serviços de saúde e na assistência aos pacientes.

O presente estudo se propõe a apresentar, por meio de uma ampla abordagem teórica, os condicionantes históricos em torno do avanço da vacinação no Brasil, o processo de defesa da população por meio de imunizantes e quais os avanços considerados pela medicina nesse processo, que tem se mostrado tão importante no período de pandemia pelo qual o mundo atravessa.

Para realizar tal intuito, optou-se por fazer uma revisão narrativa da literatura presente em bases de dados, como SciELO, PUBMED e Periódicos CAPES, através de uma busca ativa com os descritores "Vacina", "Brasil" e "História", de forma associada com o operador booleano “AND”. Já quanto aos filtros aplicados, selecionou-se os trabalhos disponíveis integralmente na forma online e os redigidos em português e inglês, além de um recorte temporal localizado entre 1993 e 2013, resultando num quantitativo de 546 trabalhos, dentre os quais 22 compuseram o referencial teórico para a elaboração do estudo em questão. Ressalta-se que alguns sites oficiais também foram componentes no processo de criação, como o da Fundação Oswaldo Cruz (Fiocruz).

\section{REVISÃO DA NARRATIVA LITERATURA}

\section{Cortiços, café e varíola: retrato do brasil no século} XIX

No século XIX aumentou a qualidade nas atividades de controle de endemias, devido o advento da microbiologia como ciência. Varíola, febre amarela e cólera que que estavam trazendo grandes transtornos para a exportação de café, onde foram doenças com rápido crescimento e tiveram-se novas ideias sobre elas. Estas epidemias ameaçavam os interesses do modelo econômico agrário-exportador, por esse motivo, vários navios mercantes, sob bandeiras estrangeiras, vinham deixando de fazer escala no país, passando afastados da costa brasileira e aportando diretamente na Argentina. Desta forma, o foco de atenção do governo brasileiro voltou-se, aos chamados espaços de circulação de mercadorias, ou seja, as estradas e portos, principalmente os do Rio de Janeiro e São Paulo (OLIVEIRA; SOUZA, 1997).

Foram surgindo sobre a etiologia, ocorrências e outros aspectos de diferentes doenças endêmicas brasileiras. Esse movimento científico, concentrado no Rio de Janeiro e em São Paulo, se fez sentir sobre o controle das doenças e para combater epidemias. A febre amarela que vinha causando epidemias constantes no Rio de Janeiro desde 1849, determinou a mais marcante das ações de controle de endemias na história no Brasil. Emílio Ribas, médico que trabalhou no combate a epidemias e endemias, buscava controlar a febre amarela nas cidades cafeeiras do estado de São Paulo, passou a empregar o controle do Aedes aegypti como estratégia única do controle da febre amarela, em São Simão. O sucesso ainda no século XIX, determinou a adoção da estratégia em outras cidades de São Paulo e, posteriormente, através de Oswaldo Cruz que 
assumiu a diretoria geral de saúde pública, convidado pelo governo de Rodrigues Alves, com ênfase no saneamento urbano da cidade do Rio de Janeiro e combate às epidemias de febre amarela, peste e varíola, no Rio de Janeiro (BENCHIMOL,1999; ALMEIDA; DANTES, 2001).

Em 1908, a febre amarela urbana havia desaparecido de São Paulo e do Rio de Janeiro, ainda que permanecesse nas cidades costeiras do Norte e Nordeste. Oswaldo Cruz começa a enfrentar as epidemias que se agravavam na cidade do Rio de Janeiro através das brigadas sanitárias, com mata-mosquitos, operários de limpeza pública, acompanhadas de soldados da polícia. As equipes caminhavam nas ruas e visitavam as casas, limpando, descontaminando, exigindo reformas, interditando prédios e removendo doentes (BENCHIMOL, 2001).

Em todas eram removidas do seu interior tudo que fosse julgado como agravo na saúde da população. As áreas mais pobres e de maior densidade demográfica eram os alvos preferidos das visitas. Os agravos calamitosos de epidemias transformavam-se em demandas políticas e pressionavam a ação estatal no âmbito saúde, mas em nenhum instante, se configurava a ideia de direito à saúde. O período que compreende a segunda metade do século XIX e primeiras décadas do século XX foi marcado por mudanças de ordem económica, social, política, cultural e espacial. Em meio a estas transformações estruturais começou a emergir da pequena cidade comercial com feição colonial uma cidade industrial com aspectos de moderna metrópole capitalista (VASCONCELOS, 2001).

Ressaltam nesta transição a substituição do trabalho escravo pelo assalariado, a formação de mercados e a mercantilização de bens, inclusive a moradia e o trabalho, a decadência da cafeicultura fluminense, o desenvolvimento dos setores secundário e terciário da economia, a definição de novas categorias sociais e a substituição de elites no poder, com a queda do império e a proclamação da República .O crescimento demográfico foi extraordinário, onde população aumentou de 235.000 habitantes em 1870 para 522.000 em 1890 (VAZ, 1994).

Vaz (1994) afirma que os trabalhadores e escravos aumentavam, libertos e imigrantes nacionais e estrangeiros que, chegando à cidade em busca de melhores meios de vida, iam para área central, onde se concentravam moradia e trabalho e fervilhava a vida urbana. Numa estrutura urbana marcada pela concentração de usos e populações, a multiplicando as habitações coletivas, ao mesmo tempo que se aproveitava desta situação, contribuía para acentuá-la.

No Rio de Janeiro, era consenso que epidemias de bexigas estavam envolvidas ao tráfico negreiro. Uma prova estava na redução do número de contaminações durante os primeiros anos da década de 1830, no vigor de um acordo anglo-brasileiro para cessação deste comércio. Entre os anos de 1827 à 1829 o número de escravos traficados seria de 135.000, mas entre 1831 a 1832, apenas algumas centenas teriam desembarcado no território nacional (VALENTIM, 1991).

As densidades demográficas e domiciliares tornaram-se cada vez mais altas. Quando aumentava a aglomeração, reduziam-se as condições de higiene no interior da habitação. As condições e a salubridade se agravavam havendo doenças como periódicas epidemias de cólera, varíola e febre amarela atingiam a cidade (VAZ, 1994).

De acordo com os estudos de Farina (1981), a vacina foi introduzida no Brasil em 1804 por iniciativa do marechal Felisberto Caldeira Brant (marquês de Barbacena), que enviou a Lisboa sete escravos e um médico a fim de que a vacina fosse transmitida, braço a braço, até a Bahia. Rodrigues (2005) afirma que esta iniciativa, não teria sido a primeira, uma vez que as vacinas já estariam em uso no Rio de Janeiro desde 
1798. Em São Paulo as datas são mais imprecisas, e a sua determinação percorre um longo período, desde o final do século XVIII até a certeza de que em 1819 já havia vacinação pública na cidade. Outros autores, ainda, estabelecem o período entre 1805 e 1811, mas para não correr grandes riscos, a grande maioria prefere mesmo dizer que a introdução da vacina em São Paulo teria ocorrido no primeiro quartel do século XIX.

A varíola esteve ausente na Corte de 1830 a 1834, mas após este período, os dados mostram um contágio ainda maior com a instituição de um comércio escravista clandestino. Através da clandestinidade, resultou impedido a vacinação dos cativos durante sua chegada ao Brasil, embora o esquema para inoculação nos portos tenha sido bem precário (CHALHUOB, 1996).

Do método jenneriano à extração via animal: evoluções e controvérsias nos processos de imunização

Os primeiros métodos de imunização da varíola remetem à prática da variolização, método de origem oriental que consistia no contato de material de pústulas de enfermos com indivíduos sadios, permitindo a obtenção da imunidade a partir de uma manifestação mais branda da varíola na pessoa inoculada. Tal método é difundido para os países ocidentais já no século XVIII, sendo amplamente adotado (REZENDE, 2009).

Posteriormente, Edward Jenner (1749-1823), médico britânico, desenvolve a vacina antivariólica em meados do século XVIII, a partir da observação de um suposto fenômeno de proteção contra a varíola desenvolvido por indivíduos que haviam tido contato pregresso com a pústula da vaca, uma doença semelhante à varíola, mas que acometia os bovinos. Diante disso, Jenner desenvolveu diversos experimentos para tentar replicar o fenômeno, chegando à obtenção de um "pus variólico", que recebeu o nome de vacina jeneriana ou humanizada (FERNANDES, 2010).

As primeiras unidades do pus variólico desembarcam em solo brasileiro no ano de 1804, acondicionadas nos corpos de sete escravos que retornavam de uma viagem até a Europa para serem inoculados, possibilitando, posteriormente, a realização de 1335 imunizações até junho de 1805 (SEQUEIRA, 1974 apud GURGEL; ROSA; CARMECINI, 2011).

De fato, a chegada do imunizante é acompanhada de uma maior preocupação estatal em relação às doenças infecciosas presentes em solo tupiniquim, principalmente a varíola, que estabeleceu a adoção de medidas com o intuito de controlar os surtos infecciosos, como a criação da Junta Vacínica da Corte, em 1811 (FERNANDES, 1999). No entanto, a resistência popular à vacinação, bem como as problemáticas inerentes ao material empregado - a vacina demandava o retorno do vacinado dia após a primeiro contato - culminaram no fracasso das medidas implementadas e permanência da disseminação da varíola (CHALHOUB, 1996 apud FERNANDES, 1999).

A introdução da vacina animal em solo brasileiro, ocorrida em 1887, coincide com um grande surto epidêmico da varíola. Nesse contexto, o médico Pedro Affonso Franco consegue a recepção de um exemplar viável da vacina, além de realizar a inoculação de 12 crianças na Santa Casa de Misericórdia do Rio de Janeiro, no dia 4 de agosto de 1887, com a vacina que já havia sido anteriormente implementada na Europa, que consiste na inoculação da pústula da vaca diretamente no indivíduo (GURGEL; ROSA; CARMECINI, 2011).

Tal panorama evidencia uma relativa evolução dos mecanismos de proteção contra a varíola, seja pela mudança no método de aplicação da vacina animal ou 
pela comprovação posterior de que o modelo animal também permitiu solucionar o problema da inativação do vírus em decorrência da vacinação "braço a braço" realizada no método jenneriano (FERNANDES, 2010). Contudo, as duas formas de inoculação apresentavam um baixo tempo de cobertura imunológica, exigindo, desse modo, revacinações para assegurar a proteção vacinal, fato que gerou revolta e insatisfação popular, associando-se tal fato à crença de que a vacina de origem transmitiria características do animal à pessoa inoculada e poderia trazer doenças próprias do animal para o ser humano (GURGEL; ROSA; CARMECINI, 2011; FERNANDES, 2010).

\section{Burocracia e saúde: criação dos primeiros órgãos de controle dos surtos de varíola}

Em 25 de maio de 1900 foi criado o Instituto Soroterápico Federal, na Fazenda de Manguinhos, na Zona Norte Rio de Janeiro, foi inaugurada inicialmente para a fabricação de soros e vacinas contra a peste bubônica. Sob a sua direção geral estava o Barão de Pedro Affonso e a direção técnica estava sob o comando de Oswaldo Cruz. Em 1902, o Barão Pedro Affonso pede exoneração do cargo e Oswaldo Cruz assume a direção geral do ISF (FIOCRUZ, 2021).

Em 1903 Oswaldo Cruz é nomeado diretor Geral de saúde pública disseminando uma reforma sanitária no Rio de Janeiro, com o intuito de combater principalmente a febre amarela e a varíola. Com isso, Manguinhos se tornou referência em saúde pública. No ano de 1904, a vacinação antivariólica torna-se obrigatória devido ao novo código sanitário, que foi reformulado por Oswaldo Cruz. Tal ato, foi duramente criticado por jornalistas e pela população em geral, que já se mostrava insatisfeita com os serviços básicos, culminando assim em protestos e com a Revolta da Vacina (FIOCRUZ, 2021).

\section{Manguinhos e revoltas: panorama da vacina no} início do século XX

O surgimento da FIOCRUZ aconteceu no período caracterizado pelo desenvolvimento da aviação e do automóvel, momento em que se inicia a chamada arte moderna. O pontapé inicial aconteceu em 22 de agosto de 1899, na qual o prefeito do Distrito Federal (Rio de Janeiro) Cesário Alvim solicitou ao Barão de Pedro Affonso, à frente do Instituto Vacínico Municipal do Rio de Janeiro (criado em 1894), a produção de soros contra a peste bubônica. Assim, em 25 de maio de 1900 nasce o Instituto Soroterápico Federal, na distante fazenda de Manguinhos, em Inhaúma, sob a direção geral do Barão de Pedro Affonso e a direção técnica de Oswaldo Cruz (FIOCRUZ, 2021).

Por volta de dois anos seguintes, após o pedido de exoneração do barão de Pedro Affonso, Oswaldo Cruz assume a direção geral do Instituto Soroterápico Federal. Nesse mesmo período o engenheiro Francisco Pereira Passos é nomeado prefeito do Rio de Janeiro, com a incumbência de fazer uma ampla reforma urbana, a fim de modernizar a cidade. Passando-se algum tempo como diretor geral, Oswaldo Cruz é nomeado pelo presidente Rodrigues Alves Diretor Geral de Saúde Pública, deflagrando campanhas de saneamento no Rio de Janeiro. Sua missão era realizar a reforma sanitária da capital, combatendo principalmente a febre amarela, a peste bubônica e a varíola (FIOCRUZ, 2021).

A ação de Cruz não se restringia a eliminar doenças e micróbios, mas realizar um saneamento que incluísse os aspectos técnico e social, ou seja, uma 'construção sociotécnica'. Isso correspondia a uma reforma completa cujo objetivo era, ao menos como projeto, realizar uma mudança que atingisse a nação em diferentes aspectos: físicos, no que tangia à higiene, mas também, intelectuais, morais, sociais e políticos. A 
grande aliada, nessa árdua tarefa, seria a ciência produzida nos países civilizados, sobretudo os da Europa do norte. Dessa parte do mundo vinha não só a ciência, mas também o modelo de civilização a seguir (CARRETA, 2011).

Empossado no cargo, o novo diretor tomou medidas urgentes para combater a febre amarela. Suspendeu todos os métodos higiênicos até então empregados e adotou a orientação definida no país caribenho, que consistia no combate ao mosquito e em isolar os amarelentos em suas residências, provendo os quartos dos doentes com telas de filó para impedir a entrada do transmissor. Medida de desinfecção complementar, já usada antes, era a queima de piretro e enxofre nas casas dos doentes, pelos quais pagava a autoridade sanitária (CARRETA, 2011).

A tentativa do médico Oswaldo Cruz de higienizar a cidade do Rio de Janeiro e impor, a partir de 1903, a obrigatoriedade da vacinação oferece rico material para análise, isso porque todo esse movimento aborreceu a vida dos habitantes dessas regiões, que eram obrigados a receber os mata-mosquitos, sair de casa para que as desinfecções fossem feitas e, no começo da operação, comprar as telas de filó para isolar eventuais doentes. Prejuízo maior tiveram os donos de estalagens e cortiços, muitos dos quais tiveram de ser reformados ou derrubados, por ordem da DGSP (CARRETA, 2011).

\section{CONSIDERAÇÕES FINAIS}

O presente estudo faz um resgate histórico através do levantamento dos eventos passados que nos trazem uma revisão histórico-cultural sobre as vacinas, sua origem e o início da sua obrigatoriedade no Brasil, apresentando a imunização como possibilidade real de proteção para os indivíduos contra as doenças infectocontagiosas da época, embora inicialmente bastante temida e alvo de conflitos e revoltas.
Destacou-se a introdução da vacina no Brasil por volta de 1804, sendo a mesma transmitida braço a braço, utilizando-se de escravos como cobaias. Também podemos encontrar na literatura consultada, seu início anteriormente, por volta do século XVIII, sendo desenvolvida através do método da variolização, de origem oriental que consistia no contato de material de pústulas de enfermos com indivíduos sadios.

$\mathrm{Na}$ segunda metade do século XIX e início do século XX, o crescimento demográfico foi crucial para acentuar a propagação de diversas doenças, tendo então Oswaldo Cruz um papel primordial na reforma sanitária do Rio de Janeiro, na Fazenda de Manguinhos. Utilizando-se de soros e vacinas para combate da peste bubônica, febre amarela e varíola, em 1904 tornou a vacinação obrigatória no Brasil, levando a manifestação popular e dando início a Revolta da vacina.

Diante disso, é possível destacar a representatividade da vacina como um grande avanço para a melhoria da saúde e qualidade de vida. Sua história é escrita continuamente, destacando cada descoberta, como uma nova possibilidade do homem obter melhores condições de vida.

\section{REFERÊNCIAS BIBLIOGRÁFICAS}

ALEXANDRE, Valentim. Portugal e a Abolição do Tráfico de Escravos. Análise Social, Lisboa, v. 26, n. 111, p. 293-333, nov. 1994. Disponível em: https://www.jstor.org/stable/41010855?seq=1. Acesso em: 18 maio 2021.

BENCHIMOL, Jaime Larry. Dos micróbios aos mosquitos. Febre amarela e a revolução pasteuriana no Brasil. Rio de Janeiro: Fiocruz/ UFRJ, 1999. 500 p.

Febre Amarela: a doença e a vacina, uma história inacabada. Rio de Janeiro: Fiocruz, 2001. 470 p. Disponível em: https://portal.fiocruz.br/livro/febre-amareladoenca-e-vacina-uma-historia-inacabada. Acesso em: 10 maio 2021. 
BERLINGUER, G. A doença como sinal. In: A doença. São Paulo: HUCITEC, 1988

CHALHOUB, Sidney. Cidade febril : cortiços e epidemias na Corte Imperial. 2. ed. São Paulo: Companhia das Letras, 1996. 288 p.

DANTES, Almeida M.; M.A.M. O serviço sanitário de São Paulo, a saúde pública e a microbiologia. Espaços da Ciência no Brasil, Editora Fiocruz, Rio de Janeiro,. 2001.

FARNA, Duílio Crispim. Medicina no planalto de Piratininga. São Paulo: Pannartz, 1981. 338 p.

FERNANDES, Tania. Vacina antivariólica: seu primeiro século no Brasil (da vacina jenneriana à animal). Hist. Cienc. Saúde -Manguinhos, Rio de Janeiro , v. 6, n. 1, p. 29-51, June 1999. Disponível em: <http://www.scielo.br/scielo.php?script=sci_a rttext\&pid $=$ S0104$59701999000200002 \& \operatorname{lng}=$ en\& $\mathrm{nrm}=$ iso $>$. Acesso em: 15 de maio de 2021

FERNANDES, T.M. Do homem ao laboratório: a construção do conhecimento científico e da técnica na produção da vacina antivariólica. Vacina Antivariólica: Ciência, Técnica e $\mathbf{O}$ Poder dos Homens, Rio de Janeiro, v. 2, p. 29-42, nov. 2010. Disponível em: https://doi.org/10.7476/9786557080955.0002.. Acesso em: 18 maio 2021.

FIOCRUZ. Linha do tempo. Disponível em: https://portal.fiocruz.br/linha-do-tempo. Acesso em: 15 mai. 2021.

GURGEL, Cristina Brandt Friedrich Martin; ROSA, Camila Andrade Pereira da; CAMERCINI, Taise Fernandes. A Varíola nos tempos de Dom Pedro II. Cadernos de Histórias da Ciência, São Paulo, v. 7, n. 1, p. 29-42, jun. 2011. Disponível em: https:/ / doi.org/10.7476/9786557080955.0002.. Acesso em: 15 maio 2021.

HOCHMAN, Gilberto. Saúde pública e construção do Estado na Primeira República. Revista Brasileira de Ciências Sociais, São Paulo, v. 14, n. 39, p. 1-261, fev. 1998. Disponível em: http://www.scielo.br/scielo.php?script=sci_art text\&pid=S0102-69091999000100012. Acesso em: 09 maio 2021.
LESSA, Sérgio de Castro; DÓREA, José Garrofe. Bioética e vacinação infantil em massa. Revista Bioética, Brasília, v. 21, n. 2, p. 226-236, ago. 2013. Disponível em: http://www.scielo.br/scielo.php?script=sci_art text\&pid $=$ S1983

80422013000200005\#: : :text=O\%20sucesso $\% 2$ 0de $\% 20$ um $\% 20$ programa $\% 20$ de $\% 20$ vacina $\%$ C3 $\%$ A7\% $\%$ C $\%$ A30 $\% 20$ em $\% 20$ massa $\% 20$ depende, vulner $\%$ C3 $\%$ A1veis $\% 2 \mathrm{C} \% 20$ como $\% 20$ crian $\%$ C3\% $\%$ 7as $\% 20 \mathrm{e} \% 20$ idosos.. Acesso em: 18 maio 2021

OLIVEIRA, Ângelo Giuseppe Roncalli da Costa; SOUZA, Elizabethe Cristina Fagundes de. A saúde no Brasil: trajetórias de uma política assistencial. Edufrn, Natal, p. 114-125, nov. 1997.

REZENDE, J. M. À sombra do plátano: crônicas de história da medicina. Varíola: Uma Doença Extinta, São Paulo, p. 227-230, 2009. Disponível em: http://books.scielo.org. Acesso em: 13 maio 2021.

SEVCENKO, Nicolau. A Revolta da vacina: mentes insanas em corpos rebeldes. São Paulo: Unesp, 1993.134 p.

SILVA, Ana Paula Freitas da et al. Educação popular e a atenção à saúde da família. Probex, São Paulo. 1999. Disponível em: http://www.prac.ufpb.br/anais/xenex_xienid/ x_enex/ANAIS/Area6/6CCSDPSPEX01.pdf. Acesso em: 12 maio 2021.

VAZ, Lilian Fessler. Dos Cortiços às Favelas e aos Edifícios de Apartamentos - A Modernização da Moradia no Rio de Janeiro. Análise Social, Rio de Janeiro, v. 3, n. 1, p. 581-598, jan. 1994. Disponível em: http:/ / memoriadasolimpiadas.rb.gov.br/jspui/ handle/123456789/899. Acesso em: 18 maio 2021. 